\title{
Reação de híbridos interespecíficos de Passiflora spp. à Xanthomonas axonopodis pv. passiflorae
}

\section{Reaction of interspecific hybrids of Passiflora spp. to Xanthomonas axonopodis pv. passiflorae}

\author{
Elisiane Fuhrmann ${ }^{\text {I* }}$ Nilton Tadeu Vilela Junqueira ${ }^{\mathrm{II}}$ Luiz Eduardo Bassay Blum ${ }^{\mathrm{I}}$ \\ Murilo Werneck Braga ${ }^{\mathrm{III}}$ Graciele Bellon ${ }^{\mathrm{I}}$ Keize Pereira Junqueira ${ }^{\mathrm{IV}}$
}

\section{RESUMO}

\begin{abstract}
Avaliou-se o grau de resistência de 36 clones de maracujazeiro obtidos por seleção massal de sete progênies de híbridos interespecíficos a três isolados de Xanthomonas axonopodis pv. passiflorae. As progênies foram obtidas por meio de cruzamentos entre a cultivar comercial Passiflora edulis "flavicarpa" com as espécies silvestres $\boldsymbol{P}$. caerulea, $\boldsymbol{P}$. edulis "roxo" $e$ P. setacea. Os isolados da bactéria foram obtidos em Rio Claro-SP, Planaltina-DF e LimeiraSP. Clones individuais foram inoculados com solução bacteriana na concentração de $10^{8}$ ufc $\mathrm{ml}^{-1}$ aos 120 dias da semeadura. As avaliações ocorreram aos 5, 10 e 15 dias após a inoculação, medindo-se o diâmetro longitudinal e transversal das lesões. Em seguida, calculou-se a área abaixo da curva de progresso da lesão (AACPL). O delineamento experimental foi em blocos ao acaso com parcelas subdivididas, sendo os genótipos os tratamentos distribuídos em quatro blocos com parcelas de três plantas para cada genótipo. Em cada parcela, plantas individuais foram inoculadas com um dos isolados da bactéria, totalizando três plantas com isolados diferentes. Plantas das espécies genitoras P. caerulea $(A A C P L=0,17)$ e P. setacea $(A A C P L=14,50)$ apresentaram alto grau de resistência, quando comparadas às plantas da testemunha BRS Gigante Amarelo (AACPL =4089,25), enquanto genótipos híbridos apresentaram valores intermediários (AACPL de 15,67 a 768,42), indicando a importância desses materiais como fontes de resistência à bacteriose.
\end{abstract}

Palavras-chave: maracujazeiro, resistência, espécies silvestres, seleção de genótipos, Passiflora caerulea, Passiflora setacea, cruzamentos interespecíficos.

\section{ABSTRACT}

The aim of this study was to evaluated the degree of resistance of 36 clones of passion obtained through mass selection progenies of seven interspecific hybrids, to three different isolates of $\boldsymbol{X}$. axonopodis pv. passiflorae. The progenies were obtained by crossing among a commercial cultivate Passiflora edulis "yellow passion fruit" with wild species $\boldsymbol{P}$. caerulea, $\boldsymbol{P}$. edulis "purple passion fruit" and P. setacea. The bacterial isolates used were obtained in Rio Claro,SP, Planaltina,DF and Limeira,SP. Individual cloned were inoculated with bacterial solution in concentration with $10^{8} \mathrm{cfu} \mathrm{ml} l^{-1}$ to 120 days of sowing. Symptoms were evaluated at 5, 10 and 15 days after inoculation, by measuring the longitudinal and transverse diameter of the lesion. Then, it was calculated the area under the lesion progress curve (AUPLC). A complete randomized block design with split plots was used, the treatments were the tested genotypes replicated in four blocks. All genotypes in each block had a three-plant plot. The bacterial isolates were inoculated in one plant of the plot, totaling three plants with different isolates. The plants of the genitors species $P$. caerulea (AUPLC $=0.17$ ) and P. setacea $(A U P L C=14.50)$ presented high degree of resistance when compared to control plants BRS 'Gigante Amarelo' (AUPLC=4089.25), while hybrids genotypes presented intermediary values (AUPLC of 15.67 the 768.42), showing the importance of these wild Passiflora species as source of resistance to bacterial disease.

Key words: passion fruit, resistance, wild species, genotype selection, Passiflora caerulea, Passiflora setacea, interspecific hybridization.

\section{INTRODUÇÃO}

O acréscimo na área cultivada com maracujazeiro tem permitido o aumento dos problemas fitossanitários a ponto de reduzir significativamente o tempo de exploração econômica da cultura (MARTINS et al., 2008). Em algumas regiões, o seu

\footnotetext{
'Universidade de Brasília (UnB), 70910-900, Brasília, DF, Brasil. E-mail: elisifuhrmann@hotmail.com. *Autor para correspondência.

IIEmpresa Brasileira de Pesquisa Agropecuária, Embrapa Cerrados, Planaltina, DF, Brasil.

IIIYara Brasil Fertilizantes, Sinop, MT, Brasil.

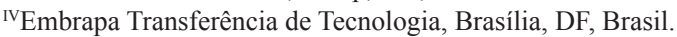


cultivo pode, inclusive, ser inviabilizado (SANTOS FILHO et al., 2004).

Xanthomonas axonopodis pv. passiflorae (PEREIRA) Dye, causador da bacteriose do maracujazeiro, é um patógeno específico do gênero Passiflora (LIBERATO, 2002). A doença afeta a parte aérea da planta e se torna mais severa em condições de altas temperaturas e umidade elevada. Os sintomas foliares iniciam-se no limbo e a infecção pode avançar através das nervuras, evoluindo para o pecíolo, até atingir os vasos dos caules mais finos, o que provoca caneluras longitudinais e a seca dos órgãos. Consequentemente, ocorre intensa desfolha e a morte prematura da planta. A bactéria pode ser introduzida e disseminada por meio de mudas infectadas, água de chuva e instrumentos de poda e de colheita (SANTOS FILHO et al., 2004; KIMATI et al., 2005).

Para o controle desta doença, a resistência genética é o método mais eficiente, econômico e ecologicamente correto. No entanto, na literatura, há poucas informações sobre resistência de maracujazeiro à bacteriose. Segundo FALEIRO et al. (2005, 2006), a identificação de fontes de resistência é a primeira etapa do melhoramento, quando se pensa na obtenção da resistência a doenças. Dessa forma, este trabalho teve como objetivo identificar e avaliar fontes de resistência à bacteriose em clones obtidos por meio de cruzamentos interespecíficos, envolvendo a cultivar comercial de maracujazeiro-azedo Passiflora edulis "flavicarpa", com as espécies silvestres $\boldsymbol{P}$. caerulea, $\boldsymbol{P}$. setacea, e P. edulis Sims "roxo".

\section{MATERIAL E MÉTODOS}

Os genótipos avaliados neste estudo foram obtidos a partir de um processo de seleção feito dentro de uma população de 630 mudas pés franco provenientes de sete progênies, obtidas por meio de cruzamentos interespecíficos (Tabela 1). Essa população foi mantida por 90 dias em casa de vegetação com nebulização intermitente a 25 $30^{\circ} \mathrm{C}$ e umidade relativa variando de 85 a $100 \%$, com ventilação, nas dependências da Embrapa Cerrados, localizada em Planaltina, DF, entre os meses de setembro de 2010 a fevereiro de 2011. Junto com essas mudas foram mantidas plantas de maracujazeiro susceptíveis e com alta incidência de bacteriose, procedentes de vários locais que contribuíram como fonte de inóculo para a infecção natural das plantas. Após avaliação do índice de incidência da doença, 315 mudas foram pré-selecionadas e plantadas em campo onde já havia plantios de maracujazeiro altamente infestados com a bacteriose e, nesses
Tabela 1 - Relação de progênies de híbridos intra e interespecíficos analisados na Embrapa Cerrados. Embrapa Cerrados, DF, 2011.

\begin{tabular}{|c|c|}
\hline Híbridos & Origem \\
\hline BRS Gigante Amarelo & $\begin{array}{l}\text { P. edulis "flavicarpa" } \times \text { P. edulis } \\
\text { "flavicarpa" }\end{array}$ \\
\hline $\mathrm{CPAC}-\mathrm{EC} 4$ & P. caerulea $\times$ P. edulis $(\mathrm{RC} 4)^{*}$ \\
\hline CPAC - ES4 & P. setacea $\times$ P. edulis $(\mathrm{RC} 4)^{*}$ \\
\hline CPAC - ES5 & P. setacea $\times$ P. edulis $(\mathrm{RC} 5)^{*}$ \\
\hline CPAC - EC5 & P. caerulea $\times$ P. edulis (RC5)* \\
\hline CPAC - ES6 & P. setacea $\times$ P. edulis (RC6)* \\
\hline CPAC - ERE & $\begin{array}{l}\text { P. edulis "flavicarpa" х } \boldsymbol{P} \text {. edulis } \\
\text { "roxo" silvestre) }\end{array}$ \\
\hline Genitor silvestre 888 & P. caerulea \\
\hline Genitor silvestre 999 & P. setacea \\
\hline
\end{tabular}

*RC4, RC5 e RC6 significam, respectivamente, quarta, quinta e sexta geração de retrocruzamentos com cultivar recorrente $(\boldsymbol{P}$. edulis "flavicarpa").

locais, foram feitas outras avaliações durante $o$ período chuvoso. Após as avaliações da bacteriose, selecionaram-se, de cada uma das progênies, as plantas mais resistentes e produtivas, com polpas de coloração vermelha, laranja ou amarelo escuro e com frutos com mais de 150 gramas. Destas 315 plantas, foram selecionadas 36 que foram clonadas e propagadas por estaquia, cultivadas em recipientes (sacos de polietileno preto) com capacidade para 1,2L e mantidas em casa de vegetação. Para favorecer o enraizamento das estacas, os recipientes receberam metade de seu volume, com uma mistura a base de solo:areia:esterco, na proporção de 4:1:1, acrescida

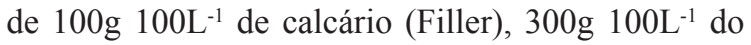
adubo 4-14-8 e metade do recipiente com o substrato Plantmax ${ }^{\circledR}$ Hortaliças.

As inoculações com os três isolados da bactéria foram realizadas quando as estacas das plantas clonadas apresentavam ramos com mais de $60 \mathrm{~cm}$ de comprimento e estavam com 120 dias de idade. Para a inoculação nos genótipos de Passiflora, foram utilizados três isolados de $\boldsymbol{X}$. axonopodis pv. passiflorae, coletados em diferentes localidades: 1 Rio Claro, SP; 2 - Limeira, SP (acesso ESALQ); e 3 Planaltina, DF (acesso Embrapa Cerrados - CPAC). Os isolados foram obtidos a partir de coleções ou plantios de maracujá e foram conservados em papel filtro pelo método da "tirinha de papel" (TAKATSU, 1994).

Para a multiplicação e obtenção de colônias puras da bactéria, tirinhas de papel contendo os isolados da bactéria foram transferidas para placas 
de Petri contendo meio de cultura 523 (KADO \& HESKETT, 1970), por meio de semeio pelo método de estrias. Em seguida, as placas foram incubadas a $28^{\circ} \mathrm{C}$ por 24 horas (LELLIOTT \& STEAD, 1987; SCHAAD, 1988). Para a obtenção da suspensão bacteriana, as colônias puras foram transferidas para tubos de plástico com fundo cônico contendo $30 \mathrm{ml}$ de água destilada e sua concentração ajustada em espectrofotômetro, a uma densidade óptica de 0,323 $\mathrm{A}_{550}\left(\sim 10^{8} \mathrm{ufc} \mathrm{ml}^{-1}\right)$, pré-determinada por meio de curva de calibração.

A inoculação dos genótipos selecionados dentro de cada progênie foi efetuada usando-se o método descrito por JUNQUEIRA (2010a), no qual um furador circular para cintos foi imerso na suspensão bacteriana $\left(\sim 10^{8} \mathrm{ufc} \mathrm{ml}^{-1}\right)$ e imediatamente utilizado para perfurar $2^{\underline{a}}, 3^{\mathrm{a}}$ e $4^{\mathrm{a}}$ folhas mais novas do ramo, produzindo orifícios regulares de 5,3mm em diâmetro, sendo um furo em cada metade do limbo foliar.

$\mathrm{O}$ delineamento experimental foi em blocos ao acaso com parcelas subdivididas, sendo os 36 clones os tratamentos repetidos em quatro blocos com parcelas de três plantas. Cada planta da parcela foi inoculada com apenas um dos isolados testados. Para cada isolado, inocularam-se 12 furos em plantasclone, dispostas nos quatro blocos. Dessa forma, a quantificação da doença em cada planta da parcela foi representada pela média de 12 orifícios. A folha mais nova do ramo não foi inoculada. No caso da testemunha, o inóculo foi substituído por água esterilizada.

Após a inoculação, as plantas foram mantidas em câmara úmida por 48 horas. Em seguida, elas permaneceram em casa de vegetação à temperatura de $25^{\circ} \mathrm{C}$ a $30^{\circ} \mathrm{C}$ e $90 \%$ - $100 \%$ de umidade relativa. As avaliações foram efetuadas aos 5, 10 e 15 dias após a inoculação, medindo-se o diâmetro transversal e longitudinal das necroses formadas em torno do orifício circular, utilizandose paquímetro digital. Em seguida, calcularam-se as áreas necrosadas pela fórmula $\mathrm{A}=\pi \mathrm{R}^{2}$, subtraiu-se a área do furo e, a partir dos dados das avaliações, calculou-se a área abaixo da curva de progresso da lesão (AACPL), conforme modelo matemático proposto por CAMPBELL \& MADDEN (1990).

A análise de variância foi feita pelo programa estatístico SISVAR e as médias foram comparadas pelo teste de Scott-Knott a $1 \%$ de probabilidade (FERREIRA, 2000).

\section{RESULTADOS E DISCUSSÃO}

Foram constatadas diferenças significativas $(\mathrm{P} \leq 1 \%)$ entre os clones de maracujazeiro, entre os isolados de $\boldsymbol{X}$. axonopodis pv. passiflorae e na interação entre genótipos e isolados. Observando a tabela 2, verifica-se que os maiores valores de área abaixo da curva de progresso da lesão (AACPL) foram apresentados nas plantas de pés franco (oriundas de sementes) da cultivar 'BRS Gigante Amarelo', escolhida como padrão de susceptibilidade, quando esta recebeu inóculo dos isolados procedentes de Rio Claro, SP $\left(2153,75 \mathrm{~mm}^{2}\right)$, Limeira, SP $\left(3412,50 \mathrm{~mm}^{2}\right)$, e Planaltina, DF $\left(6701,50 \mathrm{~mm}^{2}\right)$. Os genótipos mais susceptíveis derivados de cruzamentos entre $\boldsymbol{P}$. edulis "flavicarpa" e $\boldsymbol{P}$. caerulea apresentaram valor de AACPL bem menores que a testemunha, sendo de $814,25 \mathrm{~mm}^{2}$ quando inoculados com o isolado de Rio Claro, SP; $576,75 \mathrm{~mm}^{2}$ para o isolado Planaltina, DF; e $714,50 \mathrm{~mm}^{2}$ para o isolado de Limeira, SP. Para os clones derivados da espécie $\boldsymbol{P}$. setacea, os maiores valores de área abaixo da curva de progresso da doença foram obtidos quando se inocularam os isolados precedentes de Rio Claro, SP $\left(113,25 \mathrm{~mm}^{2}\right)$, Planaltina, DF $\left(277,00 \mathrm{~mm}^{2}\right)$ e Limeira, SP $\left(88,25 \mathrm{~mm}^{2}\right)$.

Dentro da progênie da cultivar 'BRS Gigante Amarelo', foram encontrados genótipos mais resistentes (Tabela 2). Tal fato foi relatado por JUNQUEIRA et al. (2003), que observaram baixa variabilidade para resistência a doenças entre cultivares, ao passo que, entre plantas de uma mesma cultivar, essa variabilidade era bem maior. Genótipos resistentes também foram obtidos dentro da progênie CPAC-ERE, evidenciando o potencial do acesso de $\boldsymbol{P}$. edulis "roxo" utilizado nos cruzamentos.

Verifica-se também, na tabela 2, que 22 clones dos 36 selecionados em campo apresentaram valores de AACPL menores que $81,25 \mathrm{~mm}^{2}$, valores estes mais de 50 vezes menores que os apresentados pela BRS Gigante amarelo (pé franco), considerada testemunha padrão, evidenciando elevada resistência dos clones obtidos de cruzamentos de $\boldsymbol{P}$. edulis "flavicarpa" comercial com as espécies silvestres $\boldsymbol{P}$. caerulea, $\boldsymbol{P}$. setacea e com o acesso $\boldsymbol{P}$. edulis "roxo" silvestre. Ressalta-se também a importância dessas espécies para programas de melhoramento genético de maracujazeiro azedo como fontes de resistência à bacteriose. Além disso, há um indicativo de que as resistências detectadas nos clones testados sejam governadas por genes dominantes de efeito maior, conforme preconizado por JUNQUEIRA (2010b), tendo em vista a interação significativa entre isolados e genótipos, indicando respostas diferentes dos genótipos aos isolados. Segundo LOPES et al. (2006), a resistência à bacteriose em maracujazeiro é oligogênica, porém não há variedades selecionadas 
Tabela 2 - Área abaixo da curva de progresso da lesão (AACPL) em função da área lesionada $\left(\mathrm{mm}^{2}\right)$, em 36 genótipos de maracujazeiro inoculados com três isolados de Xanthomonas axonopodis pv. passiflorae. UnB/ Embrapa Cerrados, Brasília, DF, 2011.

\begin{tabular}{|c|c|c|c|c|c|c|c|c|c|c|c|c|c|c|}
\hline \multirow{3}{*}{$\begin{array}{l}\text { Híbridos/Progênies } \\
\text { P. caerulea }\end{array}$} & \multirow{3}{*}{$\begin{array}{c}\text { Genótipos } \\
888\end{array}$} & \multirow{2}{*}{\multicolumn{3}{|c|}{-Testemunha- }} & \multicolumn{9}{|c|}{ 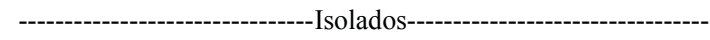 } & \multirow{3}{*}{$\begin{array}{l}\text { Médias } \\
0,17\end{array}$} \\
\hline & & & & & \multicolumn{3}{|c|}{-----Rio Claro----- } & \multicolumn{3}{|c|}{-------Planaltina----- } & \multicolumn{3}{|c|}{-------Limeira------- } & \\
\hline & & 0,0 & A & $\mathrm{a}$ & 0,00 & A & $\mathrm{a}$ & 0,25 & A & a & 0,25 & A & a & \\
\hline P. setacea & 999 & 0,0 & A & a & 0,25 & A & $\mathrm{a}$ & 21,50 & A & a & 21,75 & A & a & 14,50 \\
\hline BRS Gigante amarelo (T)(testemunha) & 777 & 0,0 & A & $\mathrm{a}$ & 2153,75 & $\mathrm{D}$ & $\mathrm{b}$ & 6701,50 & $\mathrm{~F}$ & $\mathrm{~d}$ & 3412,50 & $\mathrm{D}$ & $\mathrm{c}$ & 4089,25 \\
\hline CPAC - ES4 & 138 & 0,0 & A & $\mathrm{a}$ & 12,00 & A & a & 16,25 & A & $\mathrm{a}$ & 18,75 & A & a & 15,67 \\
\hline CPAC - ES4 & 531 & 0,0 & A & $\mathrm{a}$ & 7,00 & A & a & 22,25 & $\mathrm{~A}$ & $\mathrm{a}$ & 30,25 & A & $\mathrm{a}$ & 19,83 \\
\hline $\mathrm{CPAC}-\mathrm{EC} 4$ & 128 & 0,0 & A & a & 39,75 & A & $\mathrm{a}$ & 5,72 & $\mathrm{~A}$ & $\mathrm{a}$ & 18,75 & A & $\mathrm{a}$ & 21,41 \\
\hline CPAC - ERE & 575 & 0,0 & A & $\mathrm{a}$ & 3,00 & A & $\mathrm{a}$ & 47,00 & A & $\mathrm{a}$ & 16,25 & A & $\mathrm{a}$ & 22,08 \\
\hline BRS Gigante Amarelo (GS)* & 512 & 0,0 & A & $\mathrm{a}$ & 0,00 & A & $\mathrm{a}$ & 10,00 & $\mathrm{~A}$ & $\mathrm{a}$ & 57,00 & $\mathrm{~A}$ & $\mathrm{a}$ & 22,33 \\
\hline BRS Gigante Amarelo (GS)* & 519 & 0,0 & A & $\mathrm{a}$ & 22,00 & A & $\mathrm{a}$ & 4,00 & $\mathrm{~A}$ & $\mathrm{a}$ & 43,00 & A & $\mathrm{a}$ & 23,00 \\
\hline $\mathrm{CPAC}-\mathrm{EC} 4$ & 121 & 0,0 & $\mathrm{~A}$ & $\mathrm{a}$ & 20,00 & A & $\mathrm{a}$ & 50,75 & $\mathrm{~A}$ & $\mathrm{a}$ & 10,75 & A & $\mathrm{a}$ & 27,17 \\
\hline $\mathrm{CPAC}-\mathrm{EC} 4$ & 325 & 0,0 & A & $\mathrm{a}$ & 17,00 & A & $\mathrm{a}$ & 14,00 & A & $\mathrm{a}$ & 54,75 & A & $\mathrm{a}$ & 28,58 \\
\hline $\mathrm{CPAC}-\mathrm{EC} 4$ & 124 & 0,0 & $\mathrm{~A}$ & $\mathrm{a}$ & 10,00 & A & $\mathrm{a}$ & 20,25 & $\mathrm{~A}$ & a & 57,00 & A & $\mathrm{a}$ & 29,08 \\
\hline CPAC - ES4 & 239 & 0,0 & A & $\mathrm{a}$ & 6,25 & A & $\mathrm{a}$ & 30,50 & $\mathrm{~A}$ & $\mathrm{a}$ & 52,25 & A & $\mathrm{a}$ & 29,67 \\
\hline BRS Gigante Amarelo (GS)* & 119 & 0,0 & $\mathrm{~A}$ & $\mathrm{a}$ & 19,00 & A & $\mathrm{a}$ & 19,75 & $\mathrm{~A}$ & $\mathrm{a}$ & 51,00 & A & $\mathrm{a}$ & 29,92 \\
\hline $\mathrm{CPAC}-\mathrm{EC} 4$ & 526 & 0,0 & A & $\mathrm{a}$ & 35,25 & A & $\mathrm{a}$ & 44,75 & $\mathrm{~A}$ & $\mathrm{a}$ & 25,75 & A & $\mathrm{a}$ & 35,25 \\
\hline $\mathrm{CPAC}-\mathrm{EC} 5$ & 255 & 0,0 & $\mathrm{~A}$ & $\mathrm{a}$ & 30,50 & A & $\mathrm{a}$ & 22,75 & $\mathrm{~A}$ & a & 52,75 & A & $\mathrm{a}$ & 35,33 \\
\hline CPAC - ES4 & 233 & 0,0 & A & $\mathrm{a}$ & 6,75 & A & a & 79,25 & $\mathrm{~B}$ & $\mathrm{a}$ & 27,75 & A & a & 37,92 \\
\hline $\mathrm{CPAC}-\mathrm{EC} 5$ & 153 & 0,0 & A & $\mathrm{a}$ & 37,50 & A & $\mathrm{a}$ & 18,25 & $\mathrm{~A}$ & a & 62,00 & A & $\mathrm{a}$ & 39,25 \\
\hline CPAC - EC5 & 356 & 0,0 & A & $\mathrm{a}$ & 28,75 & A & $\mathrm{a}$ & 34,25 & A & $\mathrm{a}$ & 87,00 & A & a & 50,00 \\
\hline BRS Gigante Amarelo (GS)* & 211 & 0,0 & $\mathrm{~A}$ & $\mathrm{a}$ & 0,25 & A & $\mathrm{a}$ & 64,00 & $\mathrm{~A}$ & $\mathrm{a}$ & 86,75 & A & $\mathrm{a}$ & 50,33 \\
\hline $\mathrm{CPAC}-\mathrm{EC} 4$ & 223 & 0,0 & A & $\mathrm{a}$ & 39,00 & A & $\mathrm{a}$ & 64,00 & A & $\mathrm{a}$ & 55,75 & A & a & 52,92 \\
\hline CPAC - ES4 & 331 & 0,0 & A & $\mathrm{a}$ & 6,00 & A & $\mathrm{a}$ & 81,00 & $\mathrm{~B}$ & $\mathrm{a}$ & 75,50 & $\mathrm{~A}$ & $\mathrm{a}$ & 54,17 \\
\hline CPAC - ERE & 476 & 0,0 & A & $\mathrm{a}$ & 54,00 & A & $\mathrm{a}$ & 102,75 & B & $\mathrm{a}$ & 10,25 & A & $\mathrm{a}$ & 55,67 \\
\hline CPAC - EC5 & 455 & 0,0 & A & $\mathrm{a}$ & 138,00 & A & $\mathrm{a}$ & 90,75 & B & $\mathrm{b}$ & 4,25 & A & $\mathrm{b}$ & 77,67 \\
\hline CPAC - ES4 & 433 & 0,0 & A & $\mathrm{a}$ & 37,00 & A & $\mathrm{a}$ & 118,50 & B & $\mathrm{a}$ & 88,25 & $\mathrm{~A}$ & $\mathrm{a}$ & 81,25 \\
\hline CPAC - ES4 & 238 & 0,0 & A & $\mathrm{a}$ & 2,25 & A & $\mathrm{a}$ & 253,50 & $\mathrm{C}$ & $\mathrm{a}$ & 81,25 & A & $\mathrm{b}$ & 112,33 \\
\hline CPAC - ERE & 171 & 0,0 & A & $\mathrm{a}$ & 145,00 & A & $\mathrm{a}$ & 220,50 & $\mathrm{~B}$ & $\mathrm{~b}$ & 45,50 & A & $\mathrm{b}$ & 137,00 \\
\hline CPAC - ES5 & 546 & 0,0 & A & $\mathrm{a}$ & 113,25 & A & $\mathrm{a}$ & 277,00 & $\mathrm{C}$ & $\mathrm{a}$ & 54,75 & $\mathrm{~A}$ & $\mathrm{~b}$ & 148,33 \\
\hline CPAC - ES6 & 468 & 0,0 & A & $\mathrm{a}$ & 30,25 & A & $\mathrm{a}$ & 289,25 & $\mathrm{C}$ & $\mathrm{b}$ & 148,50 & B & $\mathrm{c}$ & 156,00 \\
\hline CPAC - EC5 & 456 & 0,0 & A & $\mathrm{a}$ & 46,25 & A & $\mathrm{a}$ & 328,25 & $\mathrm{C}$ & $\mathrm{a}$ & 115,75 & A & $\mathrm{b}$ & 163,42 \\
\hline CPAC - EC5 & 458 & 0,0 & A & $\mathrm{a}$ & 147,25 & A & $\mathrm{b}$ & 107,50 & B & $\mathrm{b}$ & 274,25 & B & $\mathrm{c}$ & 176,33 \\
\hline CPAC - ERE & 378 & 0,0 & A & $\mathrm{a}$ & 30,75 & A & $\mathrm{a}$ & 650,75 & $\mathrm{D}$ & $\mathrm{a}$ & 28,75 & A & $\mathrm{b}$ & 236,75 \\
\hline CPAC - EC5 & 157 & 0,0 & A & $\mathrm{a}$ & 28,25 & A & $\mathrm{a}$ & 94,00 & B & $\mathrm{a}$ & 714,50 & $\mathrm{C}$ & $\mathrm{b}$ & 278,92 \\
\hline CPAC - ERE & 272 & 0,0 & A & $\mathrm{a}$ & 441,75 & B & $\mathrm{a}$ & 577,75 & $\mathrm{D}$ & $\mathrm{b}$ & 69,75 & A & $\mathrm{c}$ & 363,08 \\
\hline CPAC - EC5 & 257 & 0,0 & A & $\mathrm{a}$ & 814,25 & $\mathrm{C}$ & $\mathrm{b}$ & 576,75 & $\mathrm{D}$ & $\mathrm{c}$ & 211,00 & B & $d$ & 534,00 \\
\hline CPAC - ERE & 371 & 0,0 & A & $\mathrm{a}$ & 35,25 & A & $\mathrm{a}$ & 1626,00 & E & $\mathrm{b}$ & 644,00 & $\mathrm{C}$ & $\mathrm{c}$ & 768,42 \\
\hline Médias & & 0,0 & & & 126,60 & & & 352,37 & & & 189,12 & & & \\
\hline
\end{tabular}

As médias seguidas pela mesma letra maiúscula na coluna e pela mesma letra minúscula na linha não diferem entre si, a $1 \%$ de probabilidade, pelo teste de Scott-Knott.

* BRS Gigante Amarelo (Genótipo selecionado). 
para expressar os alelos favoráveis detectados na população segregante.

JUNQUEIRA (2010b), analisando a reação de híbridos interespecíficos e das espécies silvestres P. caerulea, P.mucronata, P. vitifolia, P. gibertii, $P$. cerradense, $P$. edulis, $P$. caerulea $\times P$. edulis, $P$. caerulea $\times$ P. mucronata, $\boldsymbol{P}$. vitifolia $\times \boldsymbol{P}$. edulis e $\boldsymbol{P}$. mucronata $\times$ P. edulis a oito isolados de Xanthomonas axonopodis pv. passiflorae, procedentes de diferentes municípios, utilizando a mesma metodologia de inoculação usada neste trabalho, encontrou maior grau de resistência nas espécies silvestres e em seus híbridos. Dentre as espécies silvestres, a $\boldsymbol{P}$. caerulea foi a mais resistente, estando em conformidade com os resultados obtidos no presente estudo. Por outro lado, a cultivar 'BRS Gigante Amarelo' (pé franco) foi a mais suscetível, apresentando maiores valores de AACPL para todos os isolados, exceto para o isolado de Brasília - DF. No presente estudo, a BRS Gigante Amarelo (pé franco) também se mostrou suscetível aos três isolados testados. No entanto, dentro dessa cultivar, foram identificadas e selecionadas plantas mais resistentes.

De acordo com JUNQUEIRA at al. (2005), quanto à resistência a bacteriose, além da $\boldsymbol{P}$. actinia, outras espécies como $\boldsymbol{P}$. odontophylla, $\boldsymbol{P}$. serratodigitata, P. gibertii, $P$. caerulea, $P$. morifolia, $P$. mucronata, $\boldsymbol{P}$. tenuifila e alguns acessos de $\boldsymbol{P}$. edulis e $\boldsymbol{P}$. nitida vêm se comportando como resistentes aos isolados do Distrito Federal.

Os genótipos de maracujazeiro reagiram diferentemente aos isolados de $\boldsymbol{X}$. axonopodis pv. passiflorae. A cultivar 'BRS Gigante Amarelo' (testemunha) reagiu diferentemente aos isolados de Rio Claro, Planaltina e Limeira, sendo o isolado de Planaltina o mais agressivo. Os genótipos selecionados da BRS Gigante Amarelo (211, 512), CPAC-ES4 (233, 238, 239, 331, 531), CPAC-ERE (575) foram mais resistentes ao isolado Rio Claro, enquanto os genótipos da BRS Gigante Amarelo selecionados $(512,519)$ e CPAC-EC4 (128) foram mais resistentes ao isolado Planaltina, já os genótipos CPAC-EC5 (455), CPACERE (476) e CPAC-EC4 (121) foram mais resistentes ao isolado Limeira.

Onde houve diferença significativa entre os isolados na quantidade de doença incitada, o isolado CPAC se destacou em oito dos 13 casos (Tabela 2). Essa diferença em virulência (NELSON, 1973), constatada entre os isolados na espécie BRS Gigante Amarelo, também foi constatada no trabalho de NAKATANI et al. (2009), mostrando a existência de variabilidade na virulência dos isolados, quando inoculados em maracujá azedo. Contrariamente,
GONÇALVES \& ROSATO (2000) não encontraram variação na severidade de isolados de $\boldsymbol{X}$. axonopodis pv. passiflorae em testes de patogenicidade em $\boldsymbol{P}$. alata. Portanto, segundo NAKATANI et al. (2009), do ponto de vista prático, há necessidade de considerar a variabilidade do patógeno na avaliação de genótipos de maracujá em programas de seleção para cultivares resistentes. De acordo com esses autores, o uso de isolados mais virulentos é desejável, pois proporciona mais rigor na seleção e melhor discernimento entre genótipos resistentes e suscetíveis.

Variações em virulência ocorrem em diferentes isolados de praticamente todas as bactérias fitopatogênicas, como Xanthomonas axonopodis pv. manihotis (ALVES \& TAKATSU,1984), $\boldsymbol{X}$. campestris pv. campestris (HENZ et al.,1988) e Ralstonia solanacearum (MORGADO et al., 1992).

Neste trabalho, para os três isolados testados, os maiores valores de AACPL foram observados na espécie comercialBRS GiganteAmarelo. Possivelmente, o resultado observado independe da cultivar utilizada ('BRS Gigante Amarelo'), tendo em vista que JUNQUEIRA et al. (2003), NASCIMENTO (2003) e SOUSA (2005), trabalhando com várias cultivares comerciais de maracujá-azedo, não constataram, entre as cultivares, graus de resistência que pudessem oferecer resultados satisfatórios no controle da Passionfruit Woodiness Virus, Xanthomonas axonopodis pv. passiflorae, Colletotrichum gloeosporioides e Septoria passiflorae. Esses autores verificaram que a variabilidade para resistência a essas doenças, entre as 11 cultivares comerciais estudadas, foi muito baixa, e que pode ocorrer variabilidade genética para resistência entre plantas de uma mesma cultivar, fato que foi verificado também dentro da cv. 'BRS Gigante Amarelo'. Essa variabilidade deve ser aproveitada por meio de seleção e clonagem das plantas que se destacam dentro de cada cultivar para compor, no futuro, um próspero banco de matrizes.

\section{CONCLUSÃO}

Acultivar comercial 'BRS Gigante Amarelo' (pé franco), considerada como testemunha padrão, foi a mais suscetível à bacteriose, principalmente ao isolado CPAC de Planaltina, DF. Considerando a média obtida para a AACPL de todas as plantas avaliadas, essa cultivar foi classificada como altamente suscetível, embora algumas plantas tenham apresentado bons graus de resistência aos três isolados de Xanthomonas axonopodis pv. passiflorae testados, indicando a presença de variabilidade genética intra-específica. 
Dentre os 36 genótipos-clone, selecionados de uma população de 630 plantas, provenientes de sete progênies oriundas de cruzamentos intra e interespecíficos, 22 genótipos-clone apresentaram graus de resistência aos três isolados da bactéria, próximos aos de seus progenitores silvestres.

Os 36 genótipos-clone selecionados apresentaram valores de área abaixo da curva de progresso da lesão, semelhantes ao verificado nas espécies silvestres (P. caerulea e P. setacea), indicando que a resistência dessas espécies silvestres pode ser controlada por mais de um gene ou por um gene dominante de efeito maior, tendo em vista a interação significativa entre genótipos $\mathrm{x}$ isolados.

A resistência das espécies silvestres $\boldsymbol{P}$. caerulea, $\boldsymbol{P}$. setacea e $\boldsymbol{P}$. edulis "roxo" pode ser transferida para cultivares comerciais, como $\boldsymbol{P}$. edulis "flavicarpa", por meio de hibridações seguidas de seleções dentro das progênies.

\section{AGRADECIMENTOS}

Os autores agradecem à Empresa Brasileira de Pesquisa Agropecuária, à Universidade de Brasília e à Coordenação de Aperfeiçoamento de Pessoal de Nível Superior (CAPES).

\section{REFERÊNCIAS}

ALVES, M.L.B.; TAKATSU, A. Variabilidade em Xanthomonas campestris pv. manihotis. Fitopatologia Brasileira, v.9, p.485 494, 1984. Disponível em: <http://http://www.scielo.br/pdf/sp/ v35n2/v35n2a06.pdf>. Acesso em: 20 fev. 2011. doi:10.1590/ S0100-54052009000200006.

CAMPBELL, C.L.; MADDEN, L.V. Introducyion to plant disease epidemiology. New York: John Wiley \& Sons, 1990. 532p.

FALEIRO, F.G. et al. Importância e avanços do pré-melhoramento de Passiflora. In: LOPES, M.A. et al. (Org.). Curso internacional de pré-melhoramento de plantas. Brasília: Embrapa, 2006. p.138-142.

FALEIRO, F.G. et al. Germoplasma e melhoramento genético do maracujazeiro - desafios da pesquisa. In: FALEIRO, F.G. et al. (Eds.). Maracujá: germoplasma e melhoramento genético. Planaltina, DF: Embrapa Cerrados, 2005. p.187-210

FERREIRA, D.F. Análises estatísticas por meio do SISVAR para Windows versão 4.0. In: REUNIÃO ANUAL DA REGIÃO BRASILEIRA DA SOCIEDADE INTERNACIONAL DE BIOMETRIA, 45., 2000, São Carlos, SP. Programas e Resumos... São Carlos: UFSCar, 2000. p.235.

GONÇALVES, E.R.; ROSATO, Y.B. Genotypic characterization of Xanthomonas strains isolated from passion fruit plants (Passiflora spp.) and their relatedness to different Xanthomonas species. International Journal of Systematic and Evolutionary Microbiology (Reading), v.50, p.811-821, 2000.

HENZ, G. P. et al. Avaliação de métodos de inoculação de Xanthomonas campestris patovar campestris para detecção de fontes de resistência em brássicas. Fitopatologia Brasileira, v.13, p.207-210, 1988
JUNQUEIRA, K.P. Resistência genética e métodos alternativos de controle da bacteriose do maracujazeiro causada por Xanthomonas axonopodis pv. passiflorae. 2010a. 159f. Tese (Doutorado em Fitopatologia) - Curso de Pós-graduação em Fitopatologia, Universidade de Brasília, Brasília, DF.

JUNQUEIRA, K.P. et al. Reação de dez genótipos, incluindo espécies e híbridos interespecíficos de Passiflora, a oito isolados de Xanthomonas axonopodis pv. passiflorae. In: CONGRESSO BRASILEIRO DE FRUTICULTURA, 21, 2010, Natal, RN. Anais... Natal: Sociedade Brasileira de Fruticultura, 2010b. CDROOM

JUNQUEIRA, N.T.V. et al. Reação às doenças e produtividade de onze cultivares de maracujá-azedo cultivadas sem agrotóxico. Pesquisa Agropecuária Brasileira, v.38, p.1005-1010, 2003.

JUNQUEIRA, N.T.V. et al. Potencial de espécies silvestres de maracujazeiro como fonte de resistência a doenças. In: FALEIRO, F.G. et al. Maracujá: germoplasma e melhoramento genético. Planaltina, DF: Embrapa Cerrados, 2005. p.81-106.

KADO, C.I.; HESKETT, M.S. Selective media for isolation of Agrobacterium, Corynebacterium, Erwinia,Pseudômonas and Xanthomonas. Phytopathology, v.60, p.969-976, 1970.

KIMATI, H. et al. (Ed). Manual de fitopatologia. Doenças de plantas cultivadas. 4.ed. São Paulo: Agronomia Ceres, 2005. V.2.

LELLIOTT, R.A. \& STEAD, D.E. Methods for the diagnosis of bacterial plant disease. Oxford, Blakwell Scientific Publications. 1987. 216 p.

LIBERATO, J.R. Controle das doenças causadas por fungos, bactérias e nematóides em maracujazeiro. In: ZAMBOLIM, L. et al. (Ed). Controle de doenças de plantas fruteiras. Viçosa: Suprema, 2002. V.2. p.699-825.

LOPES, R. et al. Linkage and mapping of resistance genes to Xanthomonas axonopodis pv. passiflorae in yellow passion fruit. Genome, v.49, p.17-29, 2006

MARTINS, I. et al. Reação de genótipos de maracujazeiroamarelo ao Colletotrichum gloeosporioides. Revista Brasileira de Fruticultura, v. 30, p. 639-643, 2008.

MORGADO, H.S. et al. Virulência de isolados de Pseudomonas solanacearum à berinjela. Fitopatologia Brasileira, v.17, p.430434, 1992.

NAKATANI, A.K. et al. Variabilidade genética de Xanthomonas axonopodis pv. passiflorae. Summa Phytopathologica, v.35, p.116-120, 2009.

NASCIMENTO, A.C. Produtividade, incidência e severidade de doenças em nove genótipos de maracujazeiro-azedo sob três níveis de adubação potássica no Distrito Federal. 2003. $148 f$. Dissertação (Mestrado em Agronomia) - Curso de Pós-graduação em Agronomia, Universidade de Brasília, Brasília, DF.

NELSON, R.R. Breeding plants for disease resistance. Concepts and application. University Park: The Pennsylvania State University, 1973. p.401.

SANTOS FILHO, H.P. et al. Doenças do maracujazeiro. In: LIMA, A.A.; CUNHA, M.A.P. (Ed.). Maracujá: produção e qualidade na passicultura. Cruz das Almas: Embrapa Mandioca e Fruticultura, 2004. p.262-266. 
SCHAAD, N.W. Laboratory guide for identification of plant pathogenic bactéria. 2 ed. St. Paul, Thr American Phytopathological Society, p.157, 1988.

SOUSA, M.A.F. Produtividade e reação a doenças em genótipos de maracujazeiro-azedo, cultivados no Distrito Federal. 2005. 138f. Dissertação (Mestrado em Ciências Agrárias) - Curso de Pós-graduação em Ciências Agrárias, Universidade de Brasília, Brasília, DF.

TAKATSU, A. Coleção de bactérias fitopatogênicas preservadas pelo método de dessecação em tirinhas de papel. Informações de dez anos. Fitopatologia Brasileira, v.19, Supl., p.315, 1994. 